\title{
Los testigos patrimoniales como recursos precursores de sinergias sociales: El proyecto de cooperación al desarrollo cultural y formativo en Ecuador
}

Begoña Carrascosa becarmo@crbc.upv.es Valencia, España

\section{Olga Medina}

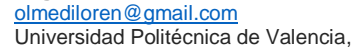

Valencia, España

\section{Cristina Nieto}

criniepr@gmail.com

Universidad Politécnica de Valencia, Valencia, España

\section{RESUMEN}

Dada la importancia de involucrar a la sociedad en la salvaguarda de su patrimonio, el proyecto Cooperación al Desarrollo Cultural y Formativo para la puesta en valor de las Pirámides Preincaicas de Cochasquí, Ecuador, estableció entre sus objetivos la sensibilización y participación de diversas comunidades con sus orígenes culturales QuituCara. Involucrando así a instituciones escolares, con la intención de realizar una serie de estudios previos respecto al actual grado de sensibilización del joven con su patrimonio, estudiando futuras vías de intervención viable y sostenible que motiven y garanticen la preservación y conservación, realizándose además acciones de capacitación al personal del Parque Arqueológico de Cochasquí en torno a la conservación de uno de los bienes culturales más importantes y significativos de Pichincha; siendo de este modo el empoderamiento cultural y la apropiación social del Patrimonio una herramienta efectiva en la salvaguarda de los bienes, y un recurso de desarrollo socio-cultural y económico local.
\end{abstract}

PALABRAS CLAVE: Desarrollo social. Sensibilización. Empoderamiento cultural. Patrimonio arqueológico. Parque Arqueológico de Cochasquí. 


\section{SIGNIFICACIONES DEL PATRIMONIO CULTURAL}

De forma habitual, reconocemos el término Patrimonio cultural como una metonimia de los objetos testimoniales fruto del devenir de culturas predecesoras. Sin embargo el término patrimonio remonta sus orígenes a la antigua época romana, en el que el pater familias legaba en herencia todo lo de la casa: el conjunto testimonial resultante previo en su último aliento. Y cosas con las que sus hijos lo recordarían en vida. Es interesante las diversas connotaciones que cada cultura a lo largo y ancho del mundo entiende el concepto de patrimonio, como por ejemplo los japoneses, quienes veneran a las personas conocedoras de la técnica, no tanto el resultado material. Las culturas europeas tienden a ajustarse más a la connotación romana, ligada a la materialidad testimonial; de ahí que se tienda mayoritariamente a la conservación de los testigos físicos, y desde 1999 también a las evidencias inmateriales.

Esta inclusión de lo inmaterial en el panorama patrimonial responde a la ampliación del concepto, entendiéndolo como cualquier evidencia de la producción humana; englobando también cuestiones como el habla, las festividades y tradiciones, o los modos de vida. Patrimonio es el resultado de la evolución cultural de la Humanidad, que de manera fortuita o intencionada, ha llegado hasta nuestros días.

Lejos de abrumar al lector con una exhaustiva disertación acerca de los orígenes del coleccionismo hasta el romanticismo europeo del s. XIX, es importante señalar que es en este momento de la Historia donde afloran las nuevas connotaciones patrimoniales: el patrimonio se convierte en símbolo de la memoria, explotando su magnitud polisémica y cualitativa; empleándose sobre todo como imagen nacional con fines políticos -construcción del estado-nación-, ya que reedifica el pasado, reinventa la tradición y sirve para la construcción de las identidades culturales de los pueblos. Se trata además de un elemento pedagógico con el que transmitir la historia y las tradiciones.

Como se desprende, es en este periodo romanticista en que el Patrimonio amplía el término hacia una concepción más antropológica: sirve de testimonio para evidenciar la cultura de los pueblos, naciendo así el patrimonio cultural que conocemos hoy en día.

"Utilizamos el término metafóricamente para referirnos a un conjunto específico de bienes que conforman el acervo social" (ARIÑO, 2002). De acuerdo a lo señalado anteriormente, son los usuarios herederos de los objetos culturales reconocen ciertos valores con los que se sienten vinculados emocional e identitariamente. De ahí que el concepto de patrimonio extienda todavía más su radio de influencia y pueda resumirse el término como relación. Relación o vínculo entre personas y culturas; entre segmentos de la línea Tiempo que conectan individuos del pasado con los sujetos del presente. Empleando como recurso de teletransporte las reliquias culturales: los objetos patrimoniales, o bienes culturales susceptibles de ser patrimonializados.

\section{EL PATRIMONIO COMO RECURSO PARA EL DESARROLLO}

La cuestión patrimonial debería contemplarse como una situación de constante conflicto debido a los retos a los que se enfrenta continuamente, tales 
como la preocupación generalizada por su supervivencia -combinada a la vez con la necesaria convivencia en la sociedad actual-, los tipos de interacción en el tejido social y la significancia que tiene en el entorno ambiental donde se ubica.

Parte del problema patrimonial radica en la funcionalidad que éste tiene para las presentes y futuras generaciones, y cómo lograr aunar objetivos y proponer metodologías sostenibles y perdurables. Es por ello que los testigos patrimoniales son importantes recursos cuya gestión además repercute positivamente en el crecimiento tanto económico como socio-cultural de las comunidades presentes del entorno inmediato, convirtiéndose así en un elemento dinamitador de sinergias para el desarrollo. Esto se traduce en intervenciones y acciones de gestión del patrimonio cultural bajo una perspectiva sistémica e integradora; es decir, cuyos efectos sean multiplicadores y positivos para la conservación del objeto patrimonial y la población heredera.

\section{LAS ACCIONES DE INTERVENCIÓN EN PATRIMONIO CULTURAL EN PROYECTOS DE COOPERACIÓN AL DESARROLLO}

"The future challenges of the conservation field will stem not only from heritage objects and sites themselves but from the context in which society embeds them. These contexts -the values people draw from them, the functions heritage objects serve for society, the uses to which heritage is put- are the real source of the meaning of heritage, and the raison d'etrê for conservation in all sense. As society changes, so does the role of conservation and the opportunities for conservation to shape and support civil society. These changed social condition compel us to think expansively and realistically about the future standing of conservation in the social agenda." (AVRAMI, 2000)

En el terreno de la Conservación del Patrimonio Cultural nos enfrentamos a retos en tres áreas:

1- La condición física:

El comportamiento de los materiales, las causas y mecanismos de degradación, cómo solucionarlo aportando tratamientos eficaces a largo plazo, etc.

2- Gestión del entorno:

Disponibilidad y uso de recursos, incluidos los fondos económicos, personal cualificado, tecnologías, condiciones de los marcos políticos y legislativos, etc.

3- Significancia cultural y valores sociales:

Por qué un objeto o lugar es significativo, para quién, quién se responsabiliza de su cuidado y mantenimiento, valorar el posible impacto de la intervención en el objeto, y cómo esto será percibido por los visitantes, etc.

El tercer aspecto es quizá el más complicado para los restauradores, ya que el oficio tiene como fin de estudio la materialidad de los objetos; no los valores intangibles adheridos. No se sopesa cómo puede influir una intervención en el entorno social y el impacto que éste puede generar. Por suerte, en la última década la Conservación ha comenzado a expandir su preocupación hacia temas la sostenibilidad de la intervención a largo plazo, la preocupación por el 
desarrollo de beneficios complementarios interrelacionados con otras áreas de la realidad, etc; que enriquecen y justifican sobradamente el importante papel del patrimonio cultural y las posibilidades que tiene como recurso económico y social.

Estas premisas son las consideradas en el caso de estudio propuesto a continuación: el Proyecto de Cooperación al Desarrollo Cultural y Formativo del Parque Arqueológico de Cochasquí, en Ecuador, en el que se ha respaldado la sostenibilidad de la intervención y la preservación del monumento con acciones sociales de sensibilización patrimonial, puesto que la presencia de lazos afectivos entre el pasado y presente garantizan la conservación del patrimonio, fortaleciendo así tanto la identidad personal como colectiva.

Como bien se define: "El Patrimonio debe orientarse al servicio de la Comunidad, es decir, para la comunidad y con la comunidad. Desde la perspectiva de la comunidad como usuaria, pero fundamentalmente como propietaria y heredera del mismo", el Patrimonio es un vestigio herencia del pasado que llega hasta nuestros días, y su estado de conservación dependerá del interés de la comunidad por preservarlo, en la medida que significa algo para los miembros conformantes, lo cual estribará su preservación: en el mayor o menor grado de relación cultural, en su intención y preocupación por recuperarlo, mantenerlo y legarlo a futuras generaciones; o de actualizar sus funciones y usos, a través de una gestión patrimonial. Estas premisas son el punto de partida que avala la sostenibilidad de cualquier acción de recuperación que realicemos.

Las acciones de recuperación arqueológica deben complementarse con actividades de difusión, sensibilización y concienciación ciudadana, fomentando así la apropiación social del Patrimonio a través de apuestas que promuevan el empoderamiento cultural de los bienes. Esto desemboca en que la comunidad desee incorporarlos a su cotidianeidad, renovando sus funciones, convirtiéndose estos usuarios en lo que se conoce como sujetos patrimoniales.

Tras un primer estudio en la materia, la transformación del usuario en sujeto patrimonial es un proceso evolutivo que precisa de dos estadios precedentes: un primer contacto o conocimiento acerca del bien, imposible de lograr sin una puesta en valor previa y una socialización o sensibilización del objeto cultural, pues no se conserva lo que no se conoce. La segunda fase correspondería al reconocimiento del bien como objeto patrimonial, y testigo por tanto de la identidad personal y colectiva de un conjunto. Por último, la integración del bien en la realidad social como ya se ha citado anteriormente, adaptando sus usos a unos presentes y demandados, introduciendo los bienes culturales dentro de la cotidianeidad a través de determinadas funciones en la actual trama o tejido social.

Además de las cuestiones técnicas ejecutadas en materia de restauración cerámica arqueológica, se exponen a continuación las acciones sociales de sensibilización yeducación patrimonial emprendidas que han contribuido a la protección, conservación y re-significación del patrimonio Quitu-Cara en el Parque Arqueológico de Cochasquí. 


\section{EL PATRIMONIO DEL PARQUE ARQUEOLÓGICO DE COCHASQUÍ, ECUADOR}

Localizado a $3100 \mathrm{msnm}$, y a $56 \mathrm{~km}$ al noreste de la ciudad de Quito, en el cantón Pedro Moncayo de la provincia de Pichincha en Ecuador, se encuentra el Parque Arqueológico y de Investigación Científica de Cochasquí. Su ubicación en las faldas del Nudo de Mojanda, entre el bosque andino y el páramo pajonal, le proporciona una ubicación excepcional y estratégica, con un campo de visión de $240^{\circ}$ del entorno.

Este complejo arqueológico arquitectónico monumental consta de 15 pirámides truncas, de las cuales 9 de ellas disponen de rampa de acceso, y 21 tolas circulares o montículos funerarios. Se corresponde al Periodo de Integración de las culturas andinas preincaicas, aproximadamente entre el 500 y el 1500 d.C. y, de acuerdo a los estudios arqueológicos realizados, correspondiente a la antigua cultura Quitu-Cara, oriunda de la provincia de Pichincha.

En la construcción de las pirámides predomina el uso de bloques de cangahua tallada (loess o toba volcánica) adheridas entre sí con chocoto apisonado. Diferenciándose del resto de asentamientos, como Socapamba o Zuleta por su interesante patrón de asentamiento urbano y su proximidad a la zona equinoccial, lo que hace pensar que posiblemente fuera destinado a la élite del lugar.

Figura 1 - Vista general de las pirámides de Cochasquí. Imagen cedida por el P.A.C.

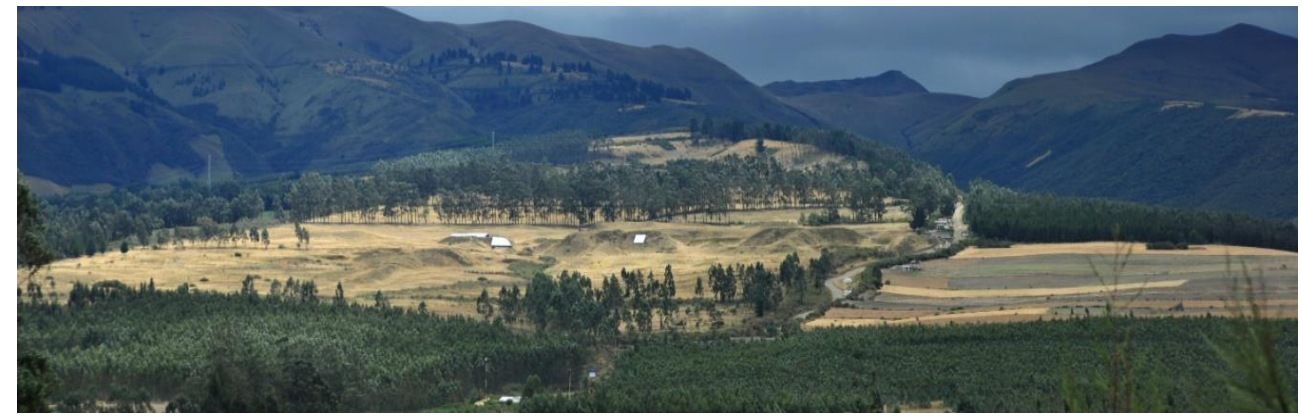

A partir de los estudios multidisciplinares que se han ido desarrollando, se hallegado a la conclusión de que nos encontramos ante unas manifestaciones arqueológicas que reflejan un gran valor histórico-cultural para el patrimonio nacional ecuatoriano. Siendo reconocido por su valor y significancia en algunas de las reuniones de la UNESCO, así como en varios foros nacionales e internacionales.

Entre sus manifestaciones arqueológicas más relevantes destacan dos plataformas cerámicas circulares, ubicadas en la cúspide de la pirámide número 13, realizadas con barro modelado y cocido in situ. Estas superficies cerámicas fueron excavadas en 1964 por el arqueólogo alemán Udo Oberem y el 'Grupo Ecuador', conformado por científicos alemanes de la Universidad de Bonn. Existen diversas hipótesis acerca del uso que pudieron desempeñar estas superficies, pero la investigación científica defendida por el astrónomo ruso Valentin Yurevich (1984), la más apoyada por la dirección del Parque Arqueológico, afirma que se tratan de dos calendarios de uso agrícola que regían la vida cotidiana de los Quitu-Cara, correspondiéndose la plataforma de mayor tamaño al sol y la menor a la luna. 
Ambas están dispuestas en alturas diferentes, distando entre ellas $1 \mathrm{~m}$., siendo la plataforma inferior de aproximadamente unos $15^{\prime} 78 \mathrm{~m}$ de diámetro, frente a los 9'75 m de la superior. En ambas encontramos prácticamente los mismos elementos: La plataforma superior presenta dos cavidades longitudinales de poca profundidad, similares a canales que forman entre sí un ángulo agudo. Dentro de estas cavidades se encuentran seis orificios agrupados de tres en tres que conforman triángulos invertidos, y en cuyo interior se colocaban conos de piedra andesita.

La estructura inferior presenta también dos canales aunque estos con quince orificios en el derecho y doce en el izquierdo, orientando la plataforma al norte.

Figura 2 - Gráfico de la pirámide 13 con la ubicación de las plataformas

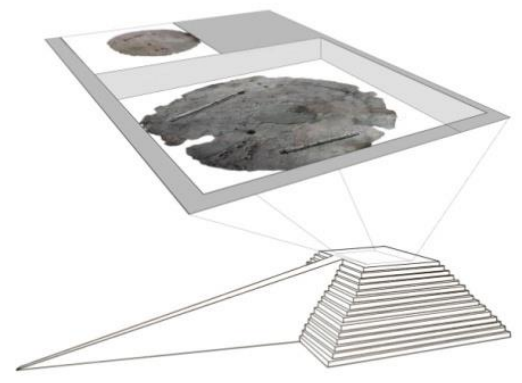

Sin embargo nos han llegado a la actualidad en un grave estado de deterioro y degradación, por diversas causas climáticas y medioambientales, biológicas y antrópicas. La dirección del Parque tomó medidas al respecto, como la construcción de un techado, vallas y cubiertas adaptadas a las necesidades de las plataformas. Pero aunque estas acciones han contribuido a la desaceleración en su degradación física, la presencia de fisuras, fragmentación cerámica, pérdida de cohesión del material, desprendimiento de fragmentos, y la presencia de microorganismos entre otras patologías, sumado al elevado nivel de humedad y los constantes vientos de la zona, han propiciado una degradación continuada en la cerámica.

Conscientes de esta situación, y de la importancia de este recurso patrimonial como elemento de desarrollo, la dirección del Parque tomó la iniciativa en generar el proyecto de recuperación bajo una perspectiva sistémica e integradora.

\section{LOS PROYECTOS DE COOPERACIÓN DE NATURALEZA SISTÉMICA}

“Un proyecto o programa de Cooperación al Desarrollo es un conjunto de acciones, localizadas geográfica y temporalmente que, previamente programadas (recursos, tiempo, secuencia...), persiguen un objetivo concreto, previamente establecido, para el inicio, apoyo o promoción del proceso de desarrollo de un determinado grupo de personas mediante colaboración en condiciones de igualdad entre varios actores" (FERRERO, 1997).

Orientado por objetivos, es imprescindible entender los hechos u obras como medios para contribuir a fines desarrollistas. En Cooperación encontramos, por lo general, dos tipologías de proyectos: los primeros cuya aportación principal es la material; y aquellos definidos según su finalidad (orientados por 
objetivos), donde los insumos y objetos materiales están supeditados a dicha finalidad. Este segundo tipo de proyectos son los conocidos como proyectos de desarrollo, y condicionados por la naturaleza de su enfoque finalista, están necesariamente diseñados bajo una perspectiva sistémica.

Esta perspectiva sistémica está implícita en el planteamiento de carácter integral de los proyectos de cooperación para el desarrollo. Considerando integral aquellos proyectos en los que las actuaciones derivadas del mismo inciden sobre varios ámbitos o sectores diferentes; como si estuvieran compuestos por varios proyectos temáticos.

Esta integralidad debe surgir en la concepción inicial del proyecto con un pensamiento o perspectiva sistémica. Se entiende por sistema aquel conjunto de elementos interrelacionados que coexisten dentro de un proyecto.

Considerar todas las relaciones entre todos los elementos del sistema es un punto clave para la consecución con éxito de los objetivos. Por ello es fundamental seguir un modelo no lineal, en el que se considere la complejidad estudiando las interrelaciones entre los diferentes aspectos del sistema.

Los elementos endógenos o actores sociales implicados se ven normalmente afectados por los elementos del entorno (exógenos) en el que coexisten. De ahí la importancia de la visión o perspectiva sistémica, aunque se trate de un proyecto o acción puntual, como es el caso del proyecto arqueológico de Cochasquí, en el cual, en torno a un objetivo material definido se desencadenan un conjunto de sinergias sociales, que al combinarse, generan un cambio actitudinal en los grupos humanos que han intervenido o interactuado con el proyecto.

Además de los beneficios de considerar los proyectos en patrimonio cultural como conjuntos complejos o sistémicos, se exponen a continuación las pautas generales que han regido este proyecto, y han sido claves en el éxito de la propuesta:

\begin{tabular}{|c|c|c|}
\hline $\begin{array}{l}\text { Principios de carácter } \\
\text { técnico y tecnológico }\end{array}$ & $\begin{array}{l}\text { Principios de carácter social } \\
\text { respecto a la comunidad } \\
\text { beneficiaria }\end{array}$ & $\begin{array}{l}\text { Principios de carácter social } \\
\text { respecto a nuestra propia } \\
\text { comunidad }\end{array}$ \\
\hline $\begin{array}{l}\text { Concepción integral } \\
\text { Visión a largo plazo } \\
\text { Propiciar el desarrollo } \\
\text { humano y ser } \\
\text { ambientalmente } \\
\text { sostenible } \\
\text { Tecnologías apropiadas }\end{array}$ & $\begin{array}{l}\text { Garantizar la participación y } \\
\text { responsabilidades } \\
\text { Las acciones del proyecto } \\
\text { deben tener en cuenta la } \\
\text { realidad socioeconómica y } \\
\text { sociocultural de los } \\
\text { beneficiarios. } \\
\text { "Mano de obra" cualificada } \\
\text { nativa } \\
\text { Fomentar la construcción de } \\
\text { tejido social local }\end{array}$ & $\begin{array}{l}\text { Contribuir a consolidar } \\
\text { nuestra propia sociedad civil } \\
\text { Promover la sensibilización y } \\
\text { la educación para el desarrollo } \\
\text { (empatía, tolerancia, } \\
\text { solidaridad) } \\
\text { Promover la interculturalidad }\end{array}$ \\
\hline
\end{tabular}




\section{EL PROYECTO DE RECUPERACIÓN Y CONSERVACIÓN ARQUEOLÓGICO}

Con todo lo expuesto anteriormente y bajo las premisas citadas, debido al interés del Parque por la protección y conservación de estos importantes testimonios se llevó a cabo el proyecto Cooperación el Desarrollo Cultural y Formativo para la Puesta en Valor de las Pirámides Preincaicas de Cochasquí, Ecuador, gracias a la subvención del Ministerio de Asuntos Exteriores de España a través de la Agencia Española de Cooperación Internacional al Desarrollo (AECID), junto a la colaboración con la Universidad Politécnica de Valencia (UPV) en España, y el Gobierno Autonómico Descentralizado de la Provincia de Pichincha, Ecuador.

El objetivo principal fue la recuperación y puesta en valor de los dos calendarios Quitu-Cara, a través de acciones de conservación y restauración, difusión y sensibilización patrimonial. Desde el Instituto Universitario de Restauración del Patrimonio (IRP) de la Universidad Politécnica de Valencia, se ha pretendido en todo momento aportar un equipo interdisciplinar con el enfoque científico-técnico necesario para llevar a cabo una intervención orientada a la recuperación y restauración adecuada de los materiales constitutivos, de acuerdo a las condiciones medioambientales y a la accesibilidad del Parque.

En la primera fase (2008-2010) se caracterizó por acciones paliativas sobre el material cerámico, cuyo objetivo fue minimizar las patologías más dañinas, y ralentizar el deterioro a partir de medidas de prevención. Entre las actividades que se llevaron a cabo destacan los tratamientos de limpieza, consolidación puntual y general, reubicación de fragmentos desprendidos, nivelación de lagunasy la realización de rebordes perimetrales de protección.

El 2012 corresponde a la segunda fase del proyecto, en la que fueron realizadas las acciones pertinentes a la restauración formal de las plataformas: limpieza, eliminación de rebordes perimetrales de protección y reconstrucción volumétrica, y aplicación de consolidante en aquellas zonas de la cerámica desprovistas de la cohesión adecuada. Ambas fases se regían por tres pilares fundamentales: el apoyo científico a través de la investigación de materiales además de la intervención en conservación y restauración in situ.

Pero lo más destacable de este proyecto no solo reside en el resultado formal de las plataformas, sino también en las diversas actividades de desarrollo socio-cultural que se han realizado, que durante todo el proceso han generado una nueva mirada más cálida y próxima hacia el Patrimonio de Cochasquí por parte de los aledaños, contemplando en estos bienes parte de su Historia y raíces culturales.

\section{ACCIONES SOCIALES EMPRENDIDAS PARA LA SOSTENIBILIDAD DEL PROYECTO}

Partiendo de la necesaria participación de la sociedad en los trabajos de recuperación arqueológica para garantizar la pervivencia de estas actividades y su sostenibilidad, las acciones acometidas tanto en la primera como en la segunda fase se han enfocado en las siguientes líneas:

1 - La formación del personal de mantenimiento del Parque, entre los que a través de una metodología teórico-práctica adquirían las destrezas y habilidades 
adecuadas que los capacita en caso de urgencia o necesidad a actuar en las plataformas, en aras de su salvaguarda.

2 - La realización de dos seminarios internacionales en la Universidad Tecnológica Equinoccial de Quito (UTE), en base a los trabajos de conservación y restauración que se estaban realizando en el Parque.

3 - Y la difusión de los trabajos realizados in situ, a través de coloquios y charlas a turistas nacionales y extranjeros, grupos escolares y universitarios que visitaban el Parque, entre los que se explicaban los tratamientos aplicados, el por qué de la intervención y la necesidad de estimar, proteger y conservar el Patrimonio.

4 - Sumado a estos trabajos de sensibilización, durante la última fase en el 2012, se desarrolló una investigación paralela en Didáctica del Patrimonio con niños y jóvenes de escuelas y colegios aledaños al Parque, con el fin de conocer el grado de identificación con el sitio arqueológico, además intentar suscitarles el interés por sus bienes culturales más cercanos (empoderamiento).

\section{FORMACIÓN Y CAPACITACIÓN}

El curso de formación estaba dirigido al personal de mantenimiento del Parque, al que a través de una metodología teórico-práctica, y bajo la supervisión del personal técnico del proyecto se les inculcaba no solo el valor cultural e identitario que los calendarios representan, sino también la metodología de trabajo en Conservación y Restauración de material cerámico arqueológico al exterior. Contribuyendo así a la capacitación en el mantenimiento y conservación in situ de las plataformas. Esto genera un prototipo de actuación extensible a otros sitios arqueológicos del entorno, conformando de este modo una red de comunidades y sitios recuperados susceptibles de generar un alto impacto en el desarrollo del territorio, probablemente a través de su vinculación al ecoturismo y turismo sostenible. Ya que son las comunidades aledañas las que como usuarios desempeñan un rol muy importante en la difusión y conservación de los bienes.

En la primera fase tres personas iniciaron sus conocimientos en extracción de material y conservación in situ, así como en tratamientos de urgencia, estabilización y consolidación del material, además de técnicas de ejecución y metodología de aplicación. Sumado todo esto a la toma de medidas preventivas, con el objetivo de minimizar los efectos de deterioro ambiental, como la facilidad de acceso, el cercado del perímetro para evitar la entrada de animales, y el levantamiento de muros.

Como resultado de esta experiencia, varios trabajadores formados en la disciplina se mantuvieron al tanto de la supervisión y mantenimiento de las estructuras, realizando trabajos periódicos de limpieza y control una vez finalizada la intervención. Gracias a las medidas preventivas tomadas en esta primera fase, la intervención se mantuvo prácticamente intacta hasta la realización de la segunda fase. 
Figura 3 - Personal de mantenimiento realizando una nivelación de lagunas

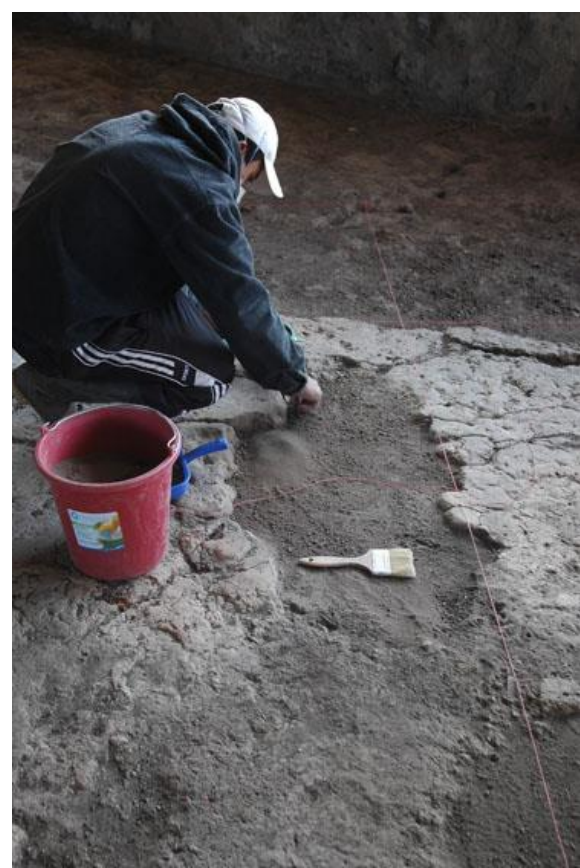

La expectación generada tras el primer curso formativo llevó a un aumento considerable en el número de participantes en la segunda capacitación del 2012, con casi el total de la plantilla. Ésta tenía por objetivo la instrucción en técnicas de restauración y reconstrucción formal, con el fin de mejorar la lectura del conjunto cerámico.

Por ello esta vez la metodología se dirigió hacia la reconstrucción formal y la adecuación de los faltantes de las estructuras. Mostrándoles y haciéndoles partícipe así en todo el proceso de estudio previo necesario para la selección del material de reposición, las pruebas previas adecuadas, además del examen visual del estado de conservación de las plataformas antes de la intervención definitiva, y las actividades de limpieza habituales. Esta formación enriquece sus conocimientos sobre el bien cultural, favoreciendo actitudes de estima y respeto. Mediante una metodología teórico-práctica y bajo la atenta supervisión y trabajo conjunto con el personal técnico del proyecto, los trabajadores adquirirían hábitos y destrezas en la ejecución del proceso de intervención, que les permitiría realizar trabajos puntuales de mantenimiento con rigor y seguridad.

Entre los conocimientos impartidos en la capacitación se destacan: 
Figura 4 - Proceso de consolidación y protección final de plataforma cerámica superior.

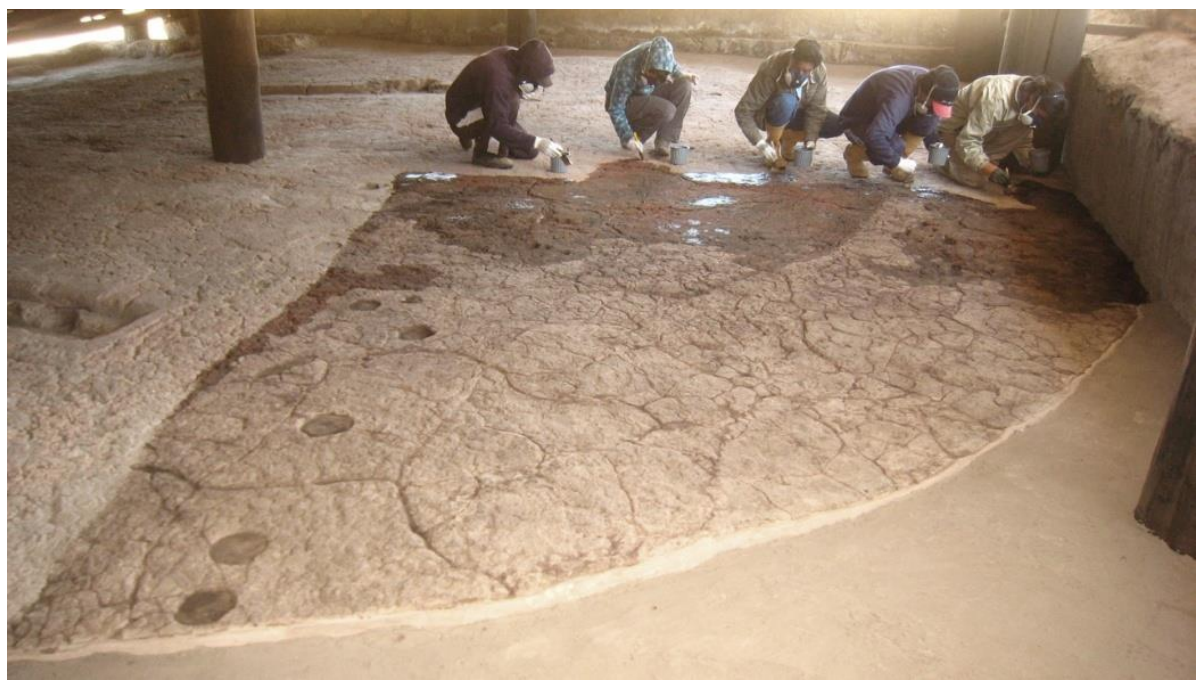

La limpieza de las plataformas cerámicas y la eliminación de tierra superficial, al igual que la metodología e instrumentación afín a cada sustrato. Las labores de limpieza es necesario hacerlas de manera periódica, más incluso tras la intervención, porque la suciedad y polvo ambiental puede generar una serie de patologías encadenadas, que favorecen al detrimento del material cerámico. Por ello es conveniente concienciar a los trabajadores de que tras la restauración es necesaria una labor de mantenimiento constante.

A su vez colaboraron en la elaboración y aplicación de morteros de relleno de lagunas, así como fueron partícipes de los estudios previos que el personal técnico del proyecto realizaba, y en la selección del material idóneo afín con el material original. Del mismo modo que se estudiaban las características del material de reposición, lo mismo ocurrió con el material de adhesión, determinando finalmente las proporciones que resultaban adecuadas para la ejecución.

Una vez seleccionado el material, trabajaron en la aplicación del relleno y realizaron distintos sistemas de estampación: aproximación formal o texturización, ya que una vez aplicado el material reintegrante sobre la laguna, éste debía ser moldeado y texturizado a semejanza con la superficie circundante, de manera que la reposición presentara un aspecto semejante al original, y de esta forma no supusiera una interrupción en la lectura de la obra.

También fueron instruidos en la fabricación de estucos para la creación de rebordes perimetrales, empleando diversos tipos de cargas atendiendo al cromatismo circundante. Al igual que en la elaboración y aplicación de adobe protector de las superficies terrosas como paredes y suelos, próximos a las plataformas cerámicas, dentro de las acciones preventivas del proyecto.

Por último, colaboraron en la aplicación del producto consolidante investigado en el laboratorio (silicato de etilo), de aplicación tanto general como puntual. Por supuesto también se les dio a conocer nociones generales para la preservación del material cerámico y añadido en la intervención, como por ejemplo la supervisión y control periódico de las estructuras. 
Figura 5 - Colocación de mortero sobre el suelo terroso, como medida preventiva de limpeza

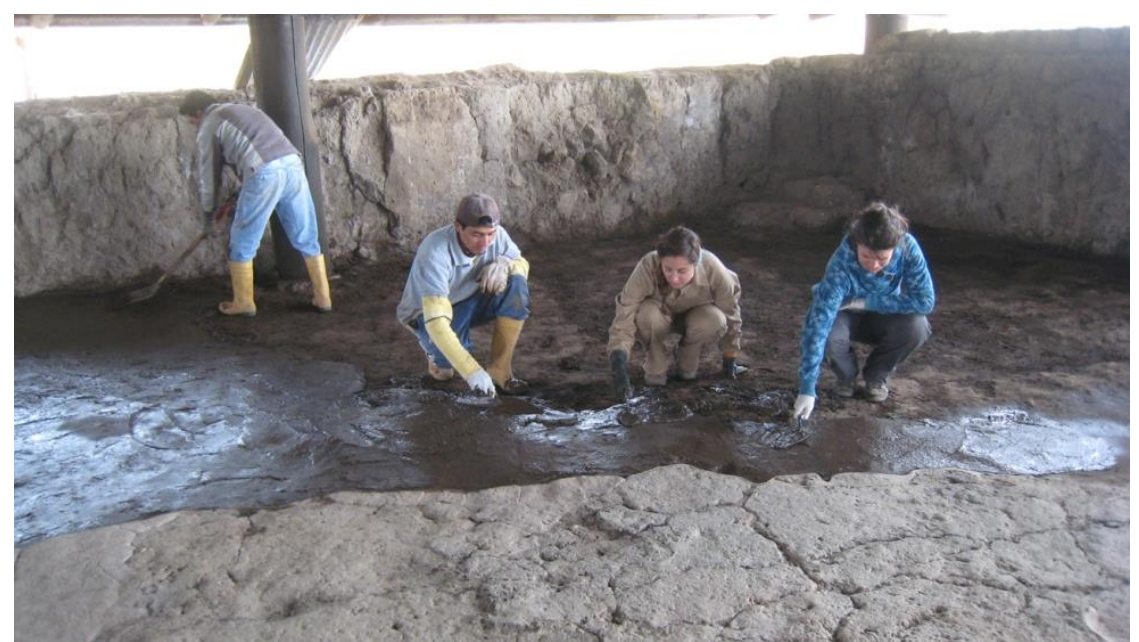

\section{SEMINARIOS INTERNACIONALES}

En la misma línea de esta capacitación, se impartió el seminario internacional "Extracción de materiales arqueológicos in situ. Iniciación a la conservación y restauración de cerámicas arqueológicas", en la Universidad Tecnológica Equinoccial de Quito (UTE). El objetivo fue inculcar entre los jóvenes estudiantes universitarios de la carrera de Restauración y Museología, y cualquier profesional interesado en la metodología de ejecución de los diferentes tratamientos de extracción de material cerámico arqueológico, y las medidas preventivas que deben ser tenidas en cuenta para minimizar el deterioro dado su ubicación al exterior.

En la segunda fase durante el 2012 se realizó un seminario internacional "Conservación y Restauración de Material Cerámico Arqueológico in situ" de carácter teórico-práctico, también en la Universidad Tecnológica Equinoccial de Quito (UTE) dirigido también a estudiantes de la disciplina y profesionales interesados, a los que se les presentaron los estudios previos, diagnóstico de las patologías, las diferentes técnicas de limpieza de material cerámico, consolidaciones por diferentes métodos, aplicaciones de reconstrucción volumétrica, y sistemas de obtención de moldes, además de los productos adecuados para la protección final al exterior, y técnicas para el control preventivo de los bienes expuestos a la intemperie. Del mismo modo, se enfatizaron los criterios deontológicos de la disciplina, como el empleo de productos inocuos, la necesaria distinción entre la intervención y el original, y la importancia de preservar la lectura del bien una vez intervenido. 


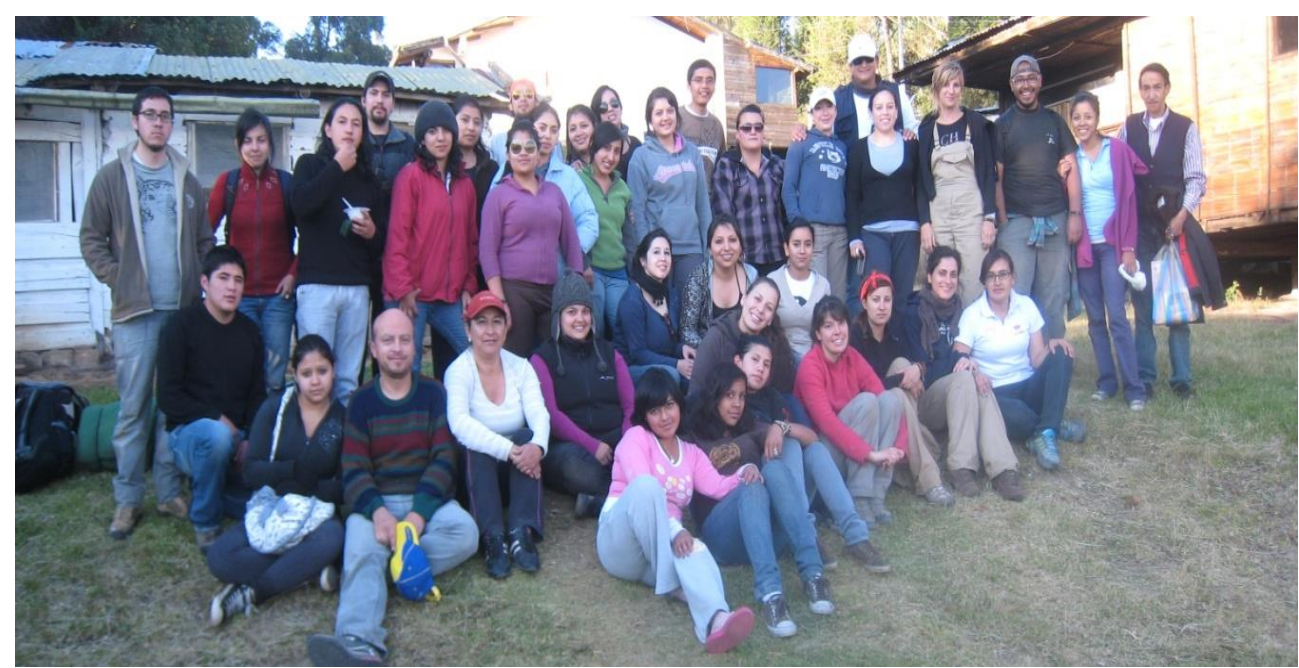

Señalar asu vez, este curso estuvo complementado con prácticas in situ en colaboración con el personal técnico del proyecto, lo que les permitió desarrollar los conceptos teóricos aprendidos, dando como resultado la sensibilización en cuanto a la dificultad que entraña la conservación de material arqueológico al exterior. El éxito del curso y las sesiones prácticas desembocó en el interés de 9 estudiantes en realizar pasantías de 3 semanas en el sitio arqueológico, en colaboración con los técnicos del proyecto y el personal trabajador del Parque Arqueológico de Cochasquí.

\section{COLOQUIOS Y CHARLAS}

Otra las actividades de difusión que se realizaron durante el periodo de ejecución de la intervención, fueron charlas y coloquios a grupos de estudiantes universitarios, turistas locales y extranjeros que visitaban el Parque, sobre las acciones que se estaban desarrollando en las plataformas, y el por qué de la intervención, junto a la necesidad de recuperar, mantener y preservar dichas estructuras, no solo por tratarse de un legado único y excepcional de los antiguos Quitu-Cara, sino por el valor cultural e identitario que representa para la actual comunidad de Cochasquí y el conjunto ecuatoriano.

Durante el periodo que abarcó la primera fase en estas charlas participaron alrededor de 764 personas, de colegios e instituciones diversas, entre las que se destacan el Colegio Nanegalito, la comunidad de Cochasquí, el colegio Francisco J. Caldas, el Ministerio de Educación, la Universidad de Ciencias Turísticas, la Escuela Superior del Ejército, la Universidad Autónoma de Quito, la Universidad Central de Quito y la Universidad Tecnológica Equinoccial de Quito. A todos ellos se les transmitió la importancia y la necesidad de conservar y proteger el Patrimonio, al igual que hacerles pensar qué pueden ellos hacer desde sus campos profesionales para salvaguardar, proteger, conservar y difundir el Patrimonio ecuatoriano.

Al igual que en la primera fase, en el 2012 se continuaron realizando dichos coloquios a aquellos visitantes y turistas interesados, a los que se les explicaban las labores de restauración que estaban siendo desarrolladas, los tratamientos 
aplicados y por supuesto, la necesidad de proteger, conservar y difundir el Patrimonio Cultural, como elemento de identidad inalienable de una comunidad que es preciso por tanto, estimar, valorar y proteger.

Figura 7 - Coloquio a los estudiantes de la Universidad de Ciencias Turísticas de Quito.

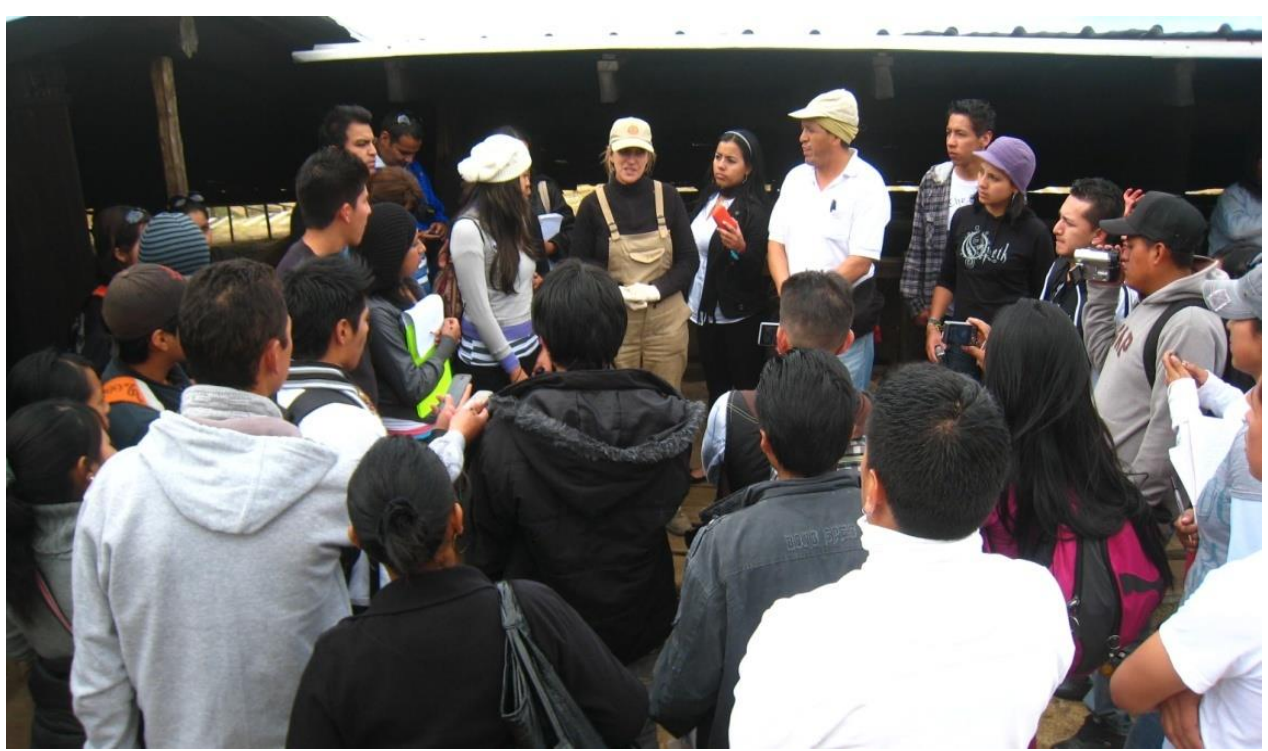

\section{ALUMNOS DE ESCUELAS Y COLEGIOS ALEDAÑOS AL PARQUE}

Por último, y objeto de investigación en el proyecto son las acciones de sensibilización destinadas a niños y jóvenes de los pueblos y aldeas cercanas al sitio arqueológico, con el fin a su vez de obtener información acerca del grado de interés de esta población juvenil con respecto al patrimonio arqueológico que los rodea. A partir de los resultados obtenidos se podría entablar y proponer unas pautas más concretas para futuras acciones de apropiación social con el entorno.

Como objetivos complementarios se destaca la aproximación del conocimiento Quitu-Cara a través de los elementos del Parque, dirigido a escolares y jóvenes alumnos de los colegios próximos al sitio arqueológico, ya que de ellos dependerá el legar estos testigos culturales en las mejores condiciones posibles, como pilares del futuro que son. Todo ello a través de una sensibilización que impulse y fortalezca la visión del joven hacia su patrimonio autóctono, y del mismo modo promueva el empoderamiento del mismo, interiorizándolo en su imaginario cultural. $Y$ dado que estas acciones se enmarcan dentro de un proyecto de recuperación y conservación de dos testigos históricoculturales, se pretendía a su vez fomentar valores de respeto y estima por el conjunto arqueológico, así como la valoración de los trabajos de conservación y restauración que se estaban realizando. Todas estas intenciones canalizadas a través de una metodología lúdico-didáctica, como técnica fundamental para el aprendizaje. Basando a su vez el trabajo en los fundamentos teóricos de Vigotsky y Brunner (aprendizaje significativo y por descubrimiento).

Los colectivos que participaron en la experiencia se localizan en los colegios y escuelas de los pueblos aledaños al sitio arqueológico, siendo la Escuela 13 de abril de la comunidad de Cochasquí, la Escuela Fiscal Mixta Pedro Moncayo y 
Colegio Nacional Malchinguí de la comunidad de Malchinguí, con un total de 612 alumnos participantes, entre edades comprendidas desde los 5 a los 18 años.

La investigación arrancó con unos estudios sobre el estado de la Educación Patrimonial en el Ecuador, además de la recopilación de estudios y experiencias previas en cuanto a experiencias en apropiación social del Patrimonio. Partiendo de unas nociones básicas en psicopedagogía y museografía didáctica, y sujetos a las condiciones y posibilidades del proyecto y el lugar. Por ello se convino realizar charlas y coloquios en las escuelas y colegios anteriormente citados, bajo un enfoque divertido, amable y atractivo que dinamizara la actividad, y que generara a su vez contexto cálido en el que los alumnos pudieran expresarse con soltura y confianza.

Para ello, desde el Instituto Universitario de Restauración del Patrimonio (IRP) en la Universidad Politécnica de Valencia en España, se estudiaron un amplio conjunto de herramientas didácticas que complementaran las charlas. Éstas fueron evaluadas por la calidad y versatilidad de sus posibilidades, y por la posible atracción que pudieran suscitar en los jóvenes, motivándoles a participar, dialogar e intervenir en los coloquios. Nuestro principal objetivo se centra principalmente en la obtención de resultados que indiquen el interés del alumnado, así como el grado de conocimiento que tienen de este patrimonio arqueológico. Y teniendo en cuenta el límite temporal de estas intervenciones, ofrecer cierta sensibilización a los escolares mediante materiales didácticos, que suscite en ellos la curiosidad y predisposición hacia el conocimiento de estos vestigios arqueológicos. Todo ello promoviendo y fortaleciendo a su vez la visión del Parque Arqueológico de Cochasquí mediante juegos y diversas actividades que fomenten valores de respeto y salvaguarda de su patrimonio, así como la valoración de los trabajos de conservación y restauración de materiales arqueológicos, enlazando el presente con la cultura Quitu-Cara (reinterpretación del Patrimonio y apropiación)

Entre todas las experiencias estudiadas dentro de las limitaciones y condicionantes del proyecto, fueron finalmente seleccionadas tres herramientas: un rompecabezas, un puzzle y unos cuadernos de trabajo.

En cuanto a los cuadernos, éstos quedaron englobados en lo que finalmentese denominó Programa "Cochasquí y Yo". Cada cuaderno disponía de fichas didácticas con ejercicios a realizar durante el desarrollo de la experiencia en el aula. Estas líneas temáticas quedaron establecidas del siguiente modo:

- Bloque I: "El cuaderno del explorador: Nuestro patrimonio cultural y natural." (5-8 años): En él se realiza una primera aproximación acerca de la diversidad de elementos que se encuentran presentes en el Parque, mediante dibujos esquemáticos, laberintos, sopa de letras, textos incompletos, etc. Estos ejercicios permiten presentar al alumno las estructuras piramidales, antes y después de su enterramiento, así como la fauna y la vegetación característica. También se invitó al alumno a incorporar el patrimonio en su entorno familiar, fortaleciendo el nexus de unión con sus vestigios arqueológicos a través del grafismo

- Bloque II: "El cuaderno del explorador: El valor cultural del Parque." (9-13 años): En él se pretende dar a conocer qué elementos engloba y se refiere el término Patrimonio, aportando una definición generalizada del concepto. Haciendo especial hincapié en sus enseres personales, para hacer posteriormente 
un paralelismo con los vestigios arqueológicos, mediante la realización de dibujos de aquellos objetos y zonas actuales que tengan una connotación especial para ellos.

- Bloque III: "El cuaderno del conservador: Cuaderno del conservador. La Conservación y Restauración." (14-18 años): En él se ha pretendido presentar las diferentes especialidades que se encargan de velar por la protección, conservación y difusión del patrimonio, mostrando la labor de los conservadoresrestauradores como una de las figuras profesionales encargadas de la preservación física del bien cultural. Sin olvidar la acción ciudadana como salvaguarda de los mismos, a través de su actitud, conducta y participación en el uso responsable con la integridad física de estos bienes. Todo ello mediante actividades como: indicar las medidas que toman para el correcto mantenimiento de los objetos valiosos que tienen en casa. Cómo afectan los agentes de deterioro a través de ilustraciones sencillas y la simulación de una rueda de prensa al conservador-restaurador con la finalidad de resolver dudas o curiosidades.

Como propuestas accesorias complementarias al Programa, se destaca la creación de:

- El rompecabezas de la Pirámide no13 (5-8 años): Se trata de una estructura piramidal que representa la Pirámide n013 donde tienen lugar las acciones de conservación y restauración de las plataformas cerámicas durante la primera y segunda fase del proyecto. En él se representan además, elementos característicos de los Quitu- Cara, fauna y flora, elementos de deterioro presentes en las construcciones y la situación actual de las medidas de conservación de las plataformas cerámicas. Este rompecabezas fue un instrumento idóneo para los alumnos más jóvenes, debido a que se trata de una propuesta dinámica e interactiva, que permite trabajar en grupo y facilita la comunicación del niño con sus compañeros y el técnico responsable. Además le facilita a éste último testar los conocimientos previos acerca del Parque, de los que parte el alumno.

- El Puzzle de la restauración (5-13 años): Es la construcción en forma ordenada de la metodología seguida en las actuaciones de conservación y restauración de las plataformas cerámicas. Los alumnos debían colocar las piezas de acuerdo al proceso empleado en la intervención, y al mismo tiempo invita a la reflexión de cada uno de los tratamientos nombrados en la herramienta. 
Figura 8 - Alumno de 2 o curso del Colegio Pedro Moncayo de Malchinguí, completando su ficha didáctica

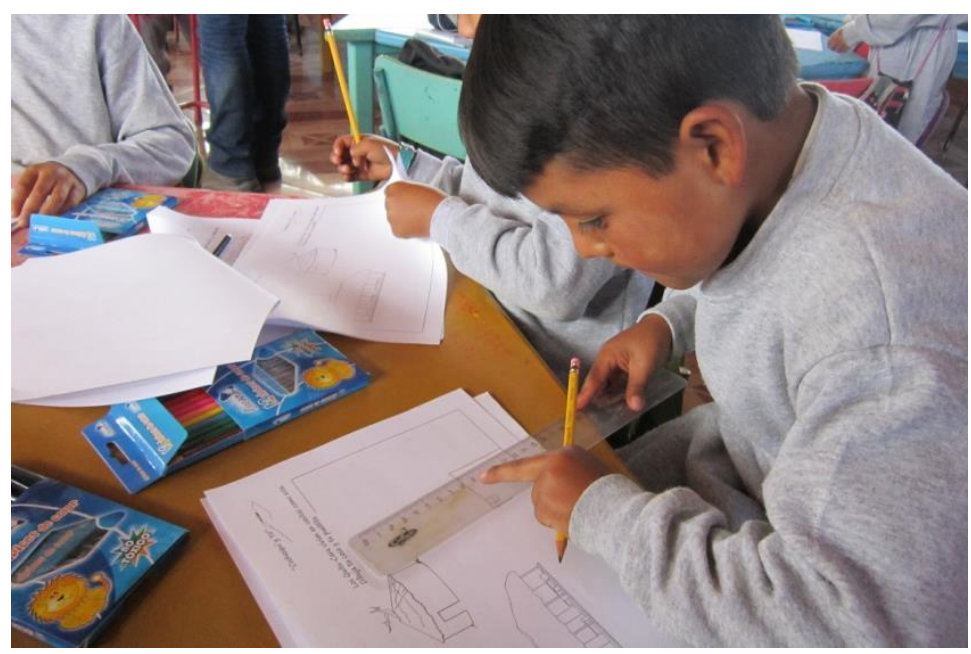

Figura 9 - Alumnos de 8o curso del Colegio Nacional de Malchinguí, realizando la encuesta final y el dibujo de libre interpretación

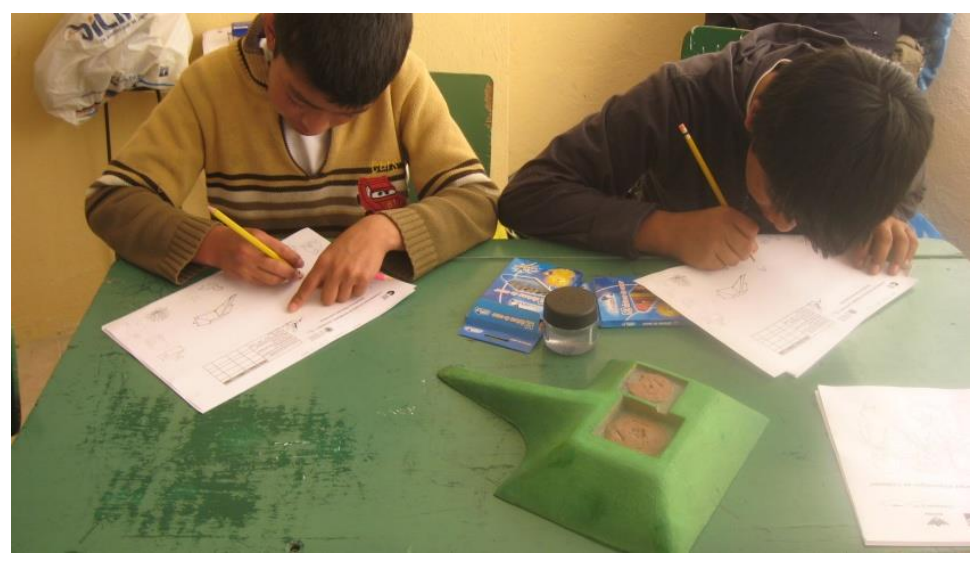

Figura 10 - Foto de grupo del 6o curso del Colegio Nacional de Malchinguí, tras la actividad

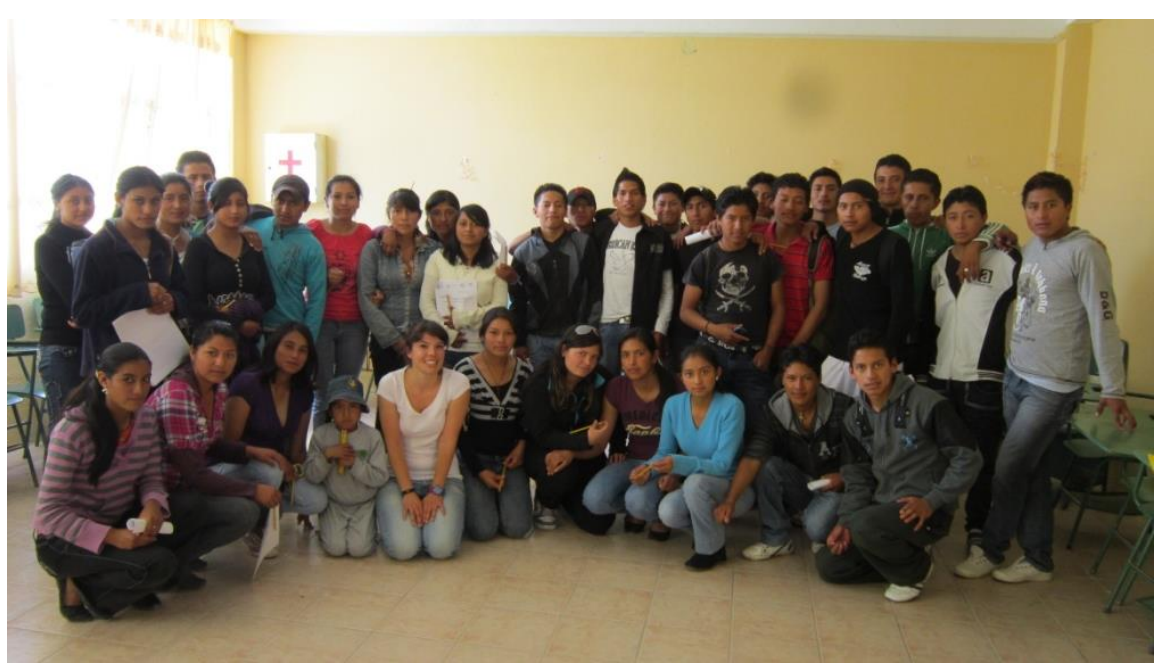




\section{RESULTADOS Y OBSERVACIONES OBTENIDAS EN LA ACTIVIDAD DIDÁCTICA EN NIÑOS Y JÓVENES}

\section{RESULTADOS PREVIOS A LA ACTUACIÓN DIDÁCTICA}

La predisposición al aprendizaje, el interés suscitado a partir de las herramientas didácticas y el amable contexto en el que se desarrollaron las actividades fueron los detonantes de esta exitosa experiencia.

Dado que nuestro interés no solo consiste en la sensibilización hacia el objeto patrimonial, sino que también se pretendía conocer el grado de interés del joven con el patrimonio arqueológico del Parque, se estableció como método de análisis la realización de breves encuestas iniciales previas a la actividad didáctica. Para así conocer la asiduidad con que visitan el Parque y el interés por conocer los testimonios Quitu-Cara presentes en el entorno en el que viven. Además de observar el grado de interés por la preservación de los testigos, y averiguar los conocimientos que tienen sobre las profesiones vinculadas a la protección, conservación y difusión del Patrimonio. Para observar los resultados de los diferentes cursos, se realizaron las encuestas atendiendo a grupos de edades, correspondiéndose estas a los bloques temáticos.

Como resultado en el primer bloque los niños muestran un alto interés por conocer estas manifestaciones; sin embargo a medida que se realizaban estas encuestas en cursos superiores, este interés disminuye. Lo mismo ocurre en cuanto a la identificación cultural con los bienes y el entorno natural en que se ubica el Parque. En los resultados del alumnado del segundo bloque, se observa que las visitas al Parque disminuyen.

En cuanto al valor cultural de estos restos arqueológicos, son conocedores de que tienen un valor inherente, pero desconocen en qué medida pueden estar vinculados con su realidad personal y comunitaria. Sobre la conducta durante las visitas al Parque, los alumnos muestran un comportamiento obediente en lo que respecta a la normativa de uso, sin embargo muchos afirman no comprender el por qué de estas prohibiciones. Tampoco distinguen las zonas en las que por seguridad y motivos de conservación es preferible limitar el paso, ni entienden en qué medida su actitud y comportamiento frente al objeto cultural, pueden afectar en su correcta preservación. 
Figura 11 - Dibujo realizado tras la experiencia, por un alumno de la Escuela 13 de Abril de Cochasquí

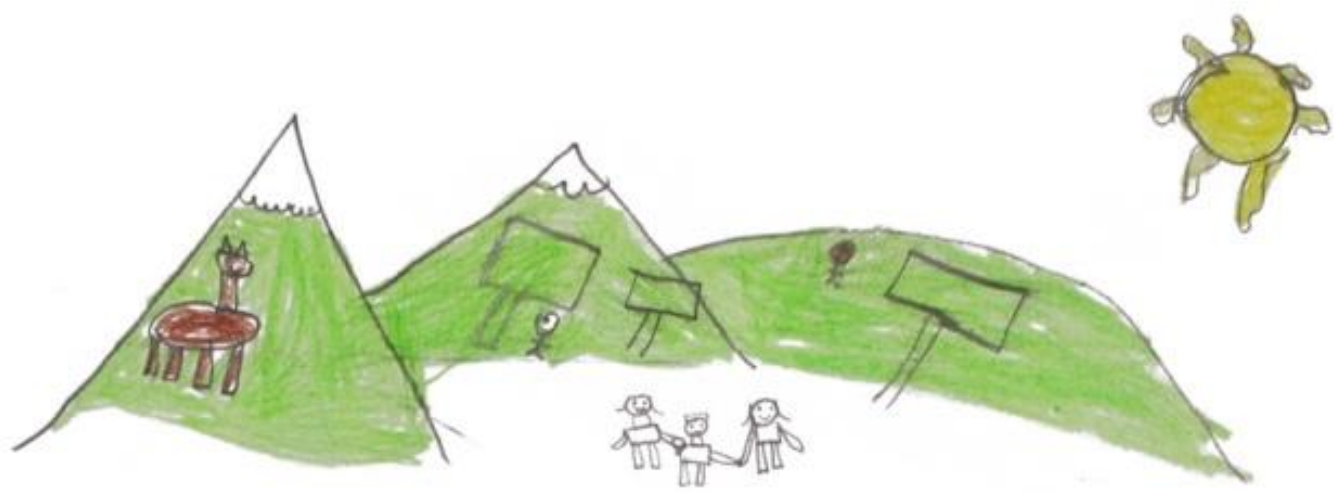

Por otra parte, alrededor del $70 \%$ de los alumnos del segundo bloque manifiesta una elevada voluntad en la salvaguarda de estos testigos culturales, pero debido mayoritariamente al importante valor económico que le atribuyen, y al importante valor histórico de los mismos. Sin embargo esta opinión es compartida por el alumnado del tercer bloque, según lo muestran las estadísticas con un $84 \%$.

Sobre los conocimientos acerca de las diferentes profesiones involucradas en el ámbito del Patrimonio Cultural y natural, los alumnos destacan la figuran del arqueólogo y la del historiador, sin embargo desconocen otras como por ejemplo, la del arquitecto, los conservadores-restauradores, el personal de mantenimiento, los guías del Parque, e incluso la propia participación ciudadana, entre otros. En este caso los porcentajes de los resultados, tanto en el segundo y el tercer bloque, son semejantes.

Figura 12 - Alumnos de la Escuela 13 de Abril de Cochasquí

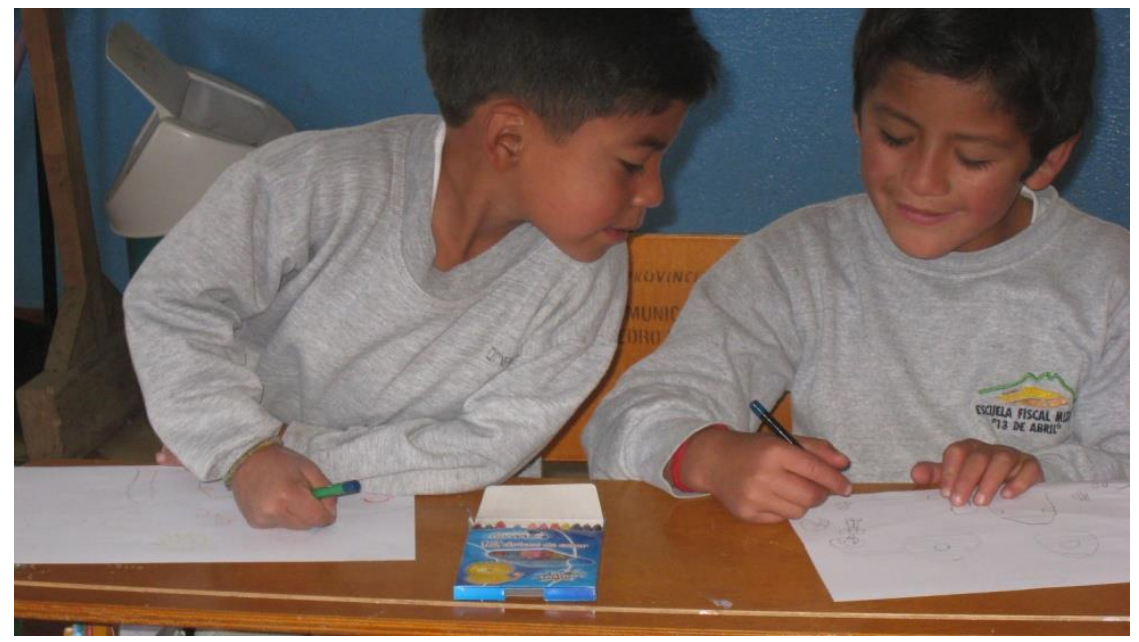

\section{RESULTADOS TRAS LA ACTUACIÓN DIDÁCTICA}

Una vez concluida la experiencia, con el fin de conocer el grado de satisfacción se realizaron unas encuestas de valoración numérica (del 1 al 5, siendo el 5 la nota más positiva), y además en el caso de los alumnos del primer y 
segundo bloque la elaboración de un dibujo de libre interpretación sobre el Parque Arqueológico de Cochasquí y los conceptos aprendidos durante la sesión. En cuanto a los alumnos del tercer bloque se les adjuntó junto a la encuesta numérica unas preguntas acerca de los tratamientos aplicados en las plataformas, de acuerdo a lo comentado durante la experiencia que, por lo general todos respondieron correctamente.

Los alumnos del Bloque I mostraron mucho entusiasmo e interés por las actividades. Cabe destacar el caso de la Escuela 13 de abril (Cochasquí) en que los alumnos reconocían muy bien los elementos del Parque, debido probablemente a las excursiones escolares al sitio y a que algunos de los familiares de los niños trabajan en el recinto arqueológico. Debido a su corta edad, la valoración del alumnado estuvo determinada a partir de los dibujos realizados tras la práctica. Siendo los elementos naturales los más representados (17\%), junto con los Bohíos (viviendas indígenas), alcanzando el mismo porcentaje, seguido de sus propias representaciones con un 16\%, incluyéndose dentro del Parque Arqueológico.

Los alumnos del Bloque II, también realizaron dibujos, donde los Bohíos se convertían en uno de los elementos más representados junto con los elementos naturales (19\%) seguido de las pirámides con un 14\%. Los alumnos participantes se mostraron sorprendidos con los paralelismos de objetos pasados con objetos presentes, manifestando una mejor comprensión en lo que supone la definición del concepto Patrimonio y la herencia cultural. Todo ello quedó reflejado en unas encuestas finales, obteniendo promedios elevados en las valoraciones de las actividades propuestas y mostrándose interesados en continuar con este tipo de planteamientos.

Los alumnos que participaron en el Bloque III manifestaron también interés durante el transcurso de la actividad, participando en grupo y lanzando cuestiones, mostrando especial sorpresa en la variedad de disciplinas que contribuyen y pueden contribuir en la protección y salvaguarda del patrimonio. También la cantidad de ámbitos que son patrimonio y la importancia que tienen para la identidad de una comunidad. Sin embargo, aunque en líneas generales la respuesta del alumnado ha sido positiva, las valoraciones posteriores obtenidas apuntan una disminución del interés por continuar con este tipo de actividades de un $23 \%$.

\section{CONCLUSIONES OBTENIDAS EN LA EXPERIENCIA CON LAS ESCUELAS Y COLEGIOS}

Teniendo en consideración los resultados obtenidos en los bloques anteriormente mencionados, se desprende que es importante aprovechar el alto interés de los más jóvenes por el conocimiento hacia el patrimonio cultural más cercano, creando y fortaleciendo lazos con los vestigios arqueológicos.

A partir de estos estudios previos, hemos podido observar como en alumnos de mayor edad, la atención y el interés hacia su patrimonio más cercano decrece, posiblemente por ser un tema no tratado de forma continua, y por tanto puede no generar motivación o preocupación alguna en los jóvenes. O quizás puede ser debido a que los recursos didácticos ofrecidos no hayan sido lo suficientemente atractivos entre los alumnos de mayor edad. Podemos decir que pese a que los 
jóvenes ven en los materiales arqueológicosun alto valor cultural sobre todo histórico, para ellos ese valor está relacionado más hacia una valía económica.

Además, éstos apenas conocían las distintas profesiones que podían estar relacionadas con el patrimonio cultural (tan solo arqueólogos e historiadores). Y pese a que son conscientes de que el patrimonio arqueológico es relevante, no saben definir en qué otros sentidos también lo es. Por lo tanto es posible que debido a este desconocimiento, no surja en ellos una preocupación e interés laboral de manera directa o indirecta hacia la protección, preservación y difusión del Patrimonio.

En cuanto a la valoración de profesorado presente en las experiencias realizadas, el $100 \%$ valora positivamente este tipo de actividades. Afirman que la identificación cultural del joven con su patrimonio es importante para su enriquecimiento educativo y cultural. Coincidiendo con los objetivos planteados en el proyecto, sobre la necesidad de fomentar este tipo de iniciativas de forma constante, mostrándose interesado en participar en futuras intervenciones, haciendo que la escuela pueda ser un eje motor en el crecimiento intelectual de las nuevas generaciones en todas sus facetas culturales, incluyendo estos conocimiento en la unidades didácticas de forma transversal en las asignaturas comunes, sin perder el carácter lúdico de las acciones, pues permiten una mayor atención del alumnado y asimilación de los conceptos, relacionando el patrimonio cultural como algo formativo a la vez que curioso, amable y divertido. Para ello sería conveniente iniciar acciones que partan desde el conocimiento y reconocimiento del objeto, para posteriormente establecer un vínculo tanto personal como colectivo. De tal modo que el alumno se sienta cómplice de la conservación tanto de su patrimonio tangible como intangible gracias a esta formación escolar que se propone.

Partiendo de las conclusiones obtenidas y como futuras vías de investigación, la Universidad Tecnológica Equinoccial de Quito UTE, ha subvencionado un proyecto en Educación Patrimonial en el que ha solicitado la colaboración del personal de este proyecto. Además del interés por parte del Parque en proseguir con el desarrollo humano, cultural y educativo de estos niños y jóvenes, en futuras colaboraciones con los colegios y escuelas cercanos al sitio arqueológico.

\section{CONCLUSIONES GENERALES Y FUTURAS LÍNEAS DE INVESTIGACIÓN}

"La reformulación del patrimonio en términos de capital cultural tiene la ventaja de no presentarlo como un conjunto de bienes estables neutros, con valores y sentidos fijos, sino como un proceso social que, como el otro capital se acumula, se renueva, produce rendimientos que los diversos sectores se apropian en forma desigual" (García Canclini, 1993)

La función original de este conjunto monumental ha cambiado en comparación con el uso de origen para el que fue creado, convirtiéndose actualmente en un espacio de memoria, con fines turísticos, además de un centro de investigación científica y de recuperación natural. Siendo un ejemplo más de cómo el patrimonio debe ser flexible a estas diferencias generacionales, y los profesionales de la gestión capaces de adaptarse a las condiciones envolventes al objeto para poder afrontar dichos retos, y lograr la supervivencia del patrimonio. Tal como se quería demostrar, diseñar acciones y actuar bajo una 
perspectiva sistémica, involucrando a los agentes sociales próximos al Parque, e invitándolos a participar de la intervención realizada, pone de relieve la viabilidad y éxito de este tipo de proyectos de desarrollo.

La nueva mirada que los habitantes adquieren como resultado de los trabajos de cooperación los convierte en actores interesados en la conservación de su patrimonio, haciéndoles sentir responsables, lo cual genera una empatía y afecto por el objeto intervenido, desembocando todo ello positivamente en la salvaguarda del mismo, garantizando la preservación del bien y de las acciones restaurativas cometidas.

En líneas generales, teniendo en cuenta los espacios sociales con los que se ha trabajado, cabe mencionar que este tipo de propuestas favorecen el incremento de la autoestima en la población de la zona por su patrimonio y en concreto, sus bienes culturales nativos más cercanos.

Todas estas propuestas y planteamientos tienen por objeto último la participación activa de la población, ya que además de propiciar la cohesión social son elementos generadores de desarrollo emocional y activación económica de la zona. El Parque Arqueológico de Cochasquí es un espacio que permite articular actividades socio-culturales y un marco actualmente utilizado para la celebración de actos de carácter cultural-religioso.

Con la incorporación de los trabajadores del Parque al proyecto se les transmite una mayor responsabilidad en la conservación de los restos, y un mejor conocimiento de la complejidad y esfuerzo que conllevan este tipo de actuaciones. En el caso de los seminarios en la Universidad, indicar que esto generó un grupo de jóvenes conocedores de las dificultades que entraña la conservación de material arqueológico in situ, y las diversas formas de abordarlo, además de acercar el Parque Arqueológico en contacto con profesionales en la disciplina, y en el ámbito universitario.

En resumen, la salvaguarda debe ser un elemento clave para la sociedad, en especial en los más jóvenes, los cuales deben implicarse de forma más activa en su patrimonio cultural, ya que además de propiciar la cohesión social, son elementos generadores de desarrollo emocional y activación económica de la zona. El primer paso hacia la verdadera apropiación social de este patrimonio arranca desde un conocimiento y estima del objeto, estableciendo un vínculo personal entre los distintos miembros de una comunidad, desarrollando el crecimiento progresivo e incluyéndolo en su entorno social y cotidiano. De tal manera que el usuario de este Patrimonio se sienta responsable en la conservación del mismo, tanto en su instancia física como en su valor cultural, como elemento de identidad personal y comunitario. Por lo tanto, dirigiendo la mirada hacia los más jóvenes, la inclusión del Patrimonio en el crecimiento educativo y personal del alumno ayuda a transformar al individuo en un sujeto patrimonial, comprometido con el cuidado y mantenimiento de estos testigos histórico-artísticos, aportando unos nuevos usos de acuerdo a la demanda actual, desde el respeto por la integridad física y potencial de la obra.

Estas estructuras arquitectónicas deben estar protegidas de acuerdo a los criterios relativos a la conservación y restauración de monumentos arqueológicos y lugares de interés cultural. La concienciación cada vez mayor del público en lo que respecta a esta dimensión fundamental del patrimonio es una necesidad absoluta si se pretenden lograr medidas concretas para la salvaguardia de los 
vestigios del pasado. Esto significa desarrollar una comprensión mayor de los valores representados por los propios Bienes Culturales, así como respetar el papel que desempeñan tales monumentos y emplazamientos en la sociedad contemporánea.

Figura 13 - Dibujo de libre interpretación de un alumno de la Escuela 13 de Abril de Cochasquí

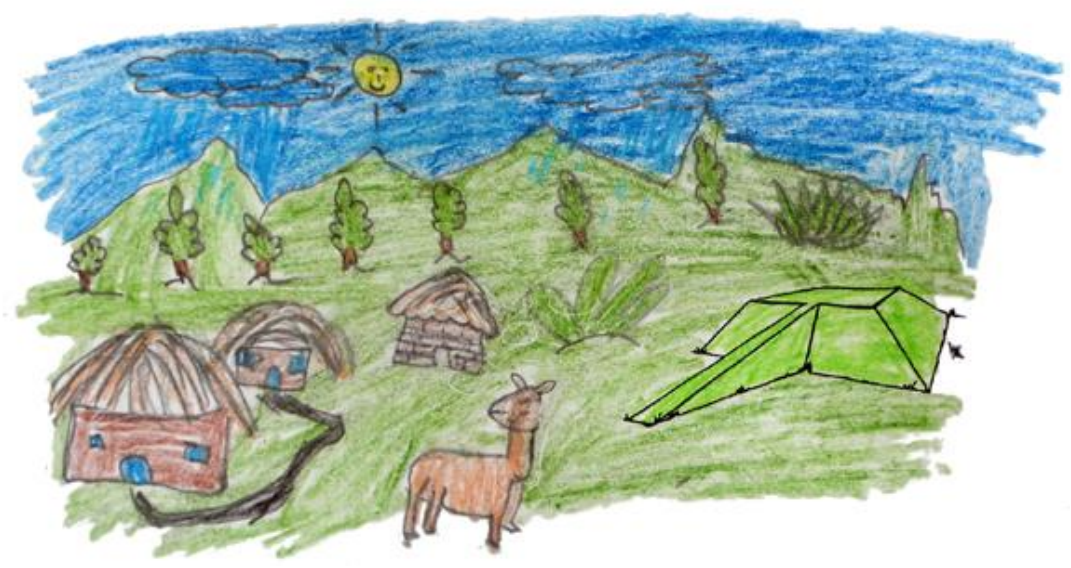

\section{AGRADECIMIENTOS}

Las autoras agradecen expresamente el apoyo recibido a la Agencia Española de Cooperación Internacional para el Desarrollo (AECID) del Ministerio de Asuntos Exteriores de España, a través de las subvenciones concedidas al Proyecto 11-CAP1-0098 y 08-CAP2-0906, y a la cofinanciación en éste por parte de La Universidad Politécnica de Valencia, España y del Gobierno Autónomo Descentralizado de la Provincia de Pichincha, Ecuador, de igual manera agradecer la participación de la Universidad Tecnológica Equinoccial de Quito (UTE) y de los colegios y escuelas participantes, que han contribuido de forma determinante a hacer posible las investigaciones y la obtención de los resultados que se exponen en esta comunicación. 


\title{
Heritage witnesses as precursos resources of social synergies: Cooperation project to cultural and formative development in Ecuador
}

\begin{abstract}
Due to the importance of involving the public in safeguarding its heritage, the Cultural and Training Development Cooperation project for the enhancement value of the preIncan Pyramids of Cochasquí, Ecuador, established among its objectives the public's awareness and sensitization with the recovery of their Quitu-Cara cultural well-beings. Moreover educational programs about Quitu-Cara culture were carried out in several schools of communities near the Archaeological Park, in order to do several previous studies to know the current level of interest the youth have with their closest heritage. Furthermore, park maintenance staff were trained in conservation and restoration works, in order to maintain the safeguard of one of the most important cultural Pichincha's monument. In this way, cultural empowerment and social appropriation of Heritage become an effective tool and guarantee of goods safeguarding, as well as local social cultural and economic development engine.
\end{abstract}

KEYWORDS: Social development. Citizen sensitization. Cultural empowerment. Archaeological Heritage. Archaeological Park of Cochasquí. 


\title{
Testemunhas patrimoniais como recursos precursores de sinergias sociais: Projeto de cooperação de desenvolvimento cultural de cooperação de formação no Equador
}

\author{
RESUMO
}

Dada a importância do envolvimento da sociedade na salvaguarda do seu patrimônio, o projeto de Cooperação Cultural e Desenvolvimento de Formação para a valorização do pré-Inca pirâmides Cochasquí, Equador, estabeleceu-se entre os seus objetivos a sensibilização ea participação de diversas comunidades com suaorigem culturalQuituCara. Envolvendo, portanto, instituições de ensino, com a intenção de realizar uma série de estudos anteriores sobre o atual nível de consciência do jovem com sua herança, estudando futuras avenidas de intervenção viável e sustentável queincentivar e garantir a preservação e conservação, também realizou atividades de capacitação funcionários Parque Arqueológico Cochasquí em torno da conservação de um dos mais importantes e significativos ativos culturais de Pichincha; assim é o fortalecimento cultural e apropriação social do Heritage uma ferramenta eficaz na salvaguarda de activos, e um recurso de desenvolvimento econômico sócio-cultural local.

PALAVRAS-CHAVE: Desenvolvimento Social. Consciência. Empoderamento cultural. Patrimônio arqueológico. Parque Arqueológico Cochasquí. 


\section{REFERENCIAS}

AAVV. Somos Patrimonio No. 4. 391 experiencias de apropiación social del patrimonio cultural y natural. Bogotá, Ed. Convenio Andrés Bello. 2004.

AVRAMI, E. et al.Values and Heritage Conservation.Los Ángeles, The Getty Conservation Institute. 2000.

BALLART, J. El Patrimonio histórico y arqueológico: valor y uso. Barcelona, Ed. Ariel Patrimonio.1997.

CARRASCOSA, B.; MEDINA, O.Mạ. Cooperación al Desarrollo Cultural y Formativo para la puesta en valor de las Pirámides preincaicas de Cochasquí, Ecuador. Valencia, Ed. Universitat Politècnica de València. 2010.

CARRASCOSA, B.; MEDINA, O.Mạ. La Conservación y Restauración de las plataformas cerámicas preincaicas de Cochasquí. II Fase: Cooperación al Desarrollo Cultural y Formativo para la puesta en valor de las Pirámides preincaicas de Cochasquí, Ecuador. Valencia, Ed. Universitat Politècnica de València. 2012.

FONTAL, O.La Educación Patrimonial. Del Patrimonio a las personas. Gijón, Ed. Trea. 2013.

FERRERO, G.Identificación y formulación de proyectos de cooperación para el desarrollo. Gestión del ciclo del proyecto y enfoque del marco lógico. Cuadernos de cooperación. Valencia, Ed. Universitat Politècnica de València. 2009.

LLONCH, N., SANTACANA, J.Claves de la museografía didáctica. Lleida, Ed. Milenio. 2011.

VIDAL, C.; VÁZQUEZ, Mạ.L.Actividades de difusión y sensibilización: Los cursos de formación como iniciativa. En: La Blanca y su entorno. Cuadernos de arquitectura y arqueología maya. Ed. Universitat Politècnica de València. 2007. 
Recebido: 08 abr. 2016

Aprovado: 10 ago. 2016

DOI: $10.3895 /$ rbpd.v5n2.4493

Como citar: CARRASCOSA, B.; MEDINA, O.;NIETO, C.. Los testigos patrimoniales como recursos precursores de sinergias sociales: El proyecto de cooperación al desarrollo cultural y formativo en Ecuador. R. bras. Planej. Desenv., Curitiba, v. 5, n. 2, p. 219-245, mai./ago. 2016. Disponível em: $<$ https://periodicos.utfpr.edu.br/rbpd>. Acesso em: XXX.

\section{Correspondência:}

Begoña Carrascosa

Campus de Vera, Camino de Vera, s/n, 46022, Valencia, España

Direito autoral: Este artigo está licenciado sob os termos da Licença CreativeCommons-Atribuição 4.0 Internacional.

\section{(c) (1)}

